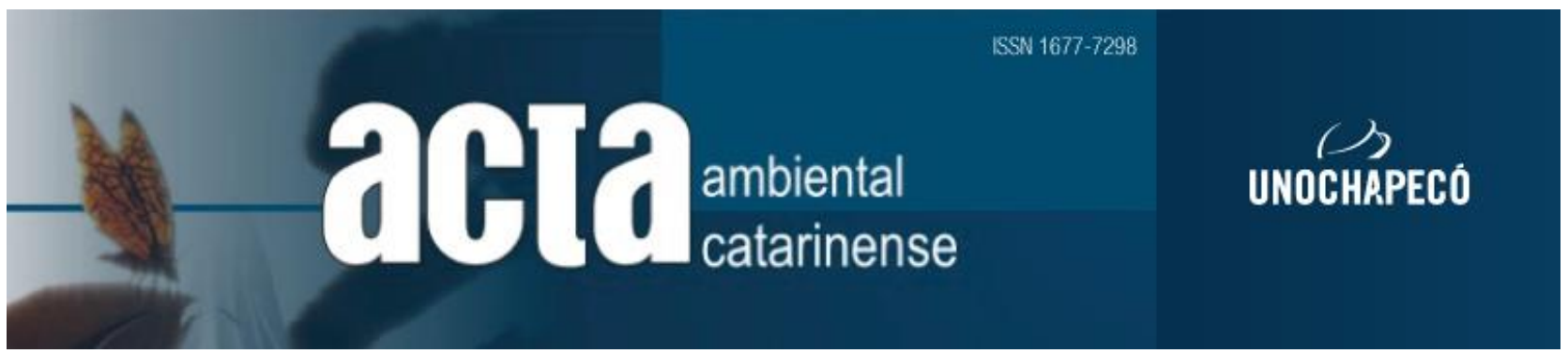

\title{
GESTÃO DE RESÍDUOS SÓlIDOS URBANOS: ENTRAVES PARA implantaÇão da Política Nacional de Resíduos Sólidos No MUNICÍPIO DE ITINGA DO MARANHÃO - MA
}

\author{
Ivamírian da Conceição Ramalho Ximendes ${ }^{1}$ \\ Maria de Fátima Sousa Silva ${ }^{2}$ \\ Airton Pereira da Silva Leão ${ }^{3}$ \\ Stefeni da Conceição Ramalho ${ }^{4}$ \\ Francisco Diego Feitosa de Souza ${ }^{5}$
}

\begin{abstract}
Resumo
A implantação da Política Nacional de Resíduos Sólidos (PNRS) tornou-se um grande desafio para muitos municípios brasileiros, especialmente para os de pequeno porte; nessa perspectiva, o presente trabalho teve por objetivo analisar a gestão de resíduos sólidos de Itinga do Maranhão - MA, buscando identificar os possíveis entraves existentes por meio de uma análise documental e da realização de um estudo de caso com a aplicação de um questionário semi-estruturado. Os resultados obtidos permitiram a compreensão da gestão municipal dos resíduos sólidos, que está fundamentada no cumprimento das metas, diretrizes e objetivos da PNRS. Dessa forma, a partir da realização da pesquisa foi possível diagnosticar que há a execução de ações e programas conforme as competências da esfera municipal previstas em lei. Embora a gestão tenha se mostrado efetiva na implantação da PNRS, muitos programas ainda se encontram em processo de implementação e os entraves existentes concentram-se na ausência da participação da sociedade e na escassez de incentivos federais, demandando um maior comprometimento dos gestores em busca da máxima efetivação das ações desenvolvidas.
\end{abstract}

Palavras-chave: Resíduos sólidos; Desenvolvimento sustentável; Gestão.

\footnotetext{
${ }^{1}$ Especialista em Gestão Pública pela Universidade Federal do Maranhão (UFMA) e Graduada em Engenharia Florestal pela Universidade Estadual do Maranhão (UEMA)

${ }^{2}$ Doutoranda em Educação UNESP, Graduada em Pedagogia pela Universidade Estadual do Maranhão UEMA

${ }^{3}$ Professor titular da Faculdade Vale do Aço - FAVALE

${ }^{4}$ Graduada em Engenharia Agronômica pela Universidade da Região Tocantina do Maranhão - UEMASUL

${ }^{5}$ Professor do Instituto Federal do Pará - IFPA.
} 


\begin{abstract}
The implementation of the National Solid Waste Policy (PNRS) has become a major challenge for many Brazilian municipalities, especially for small ones; in this perspective, the present work aimed to analyze the solid waste management of Itinga do Maranhão - MA, seeking to identify the possible existing obstacles through a documentary analysis and the realization of a case study with the application of a semi-questionnaire structured. The results obtained allowed the understanding of the municipal solid waste management, which is based on the fulfillment of the PNRS goals, guidelines and objectives. Thus, from the realization of the research it was possible to diagnose that there is the execution of actions and programs according to the competences of the municipal sphere provided for by law. Although management has been shown to be effective in implementing the PNRS, many programs are still in the process of being implemented and the existing barriers are concentrated in the absence of participation by society and in the scarcity of federal incentives, demanding greater commitment from managers in search of maximum effectiveness of the actions developed.
\end{abstract}

Keywords: Solid waste; Sustainable development; Management.

\section{INTRODUÇÃo}

O ritmo acelerado das mudanças sociais, econômicas, políticas, culturais, ambientais e tecnológicas induzem ao aumento das dificuldades e desafios que são de responsabilidade do poder público. Nesse contexto, torna-se necessário que a intensa urbanização e suas transformações socioambientais sejam acompanhadas por práticas que priorizem um desenvolvimento sustentável, com metas que vão desde o âmbito socioeconômico ao governamental, do meio ambiente, tecnológico e cultural (BARROS; SOUZA, 2017).

O crescimento demográfico está diretamente relacionado com o aumento do consumo, este por sua vez é visto como um elo entre a população e a geração de resíduos. $\mathrm{O}$ consumo elevado resulta em um maior quantitativo de resíduos descartados e se diferencia em função de fatores como a faixa etária, renda e escolaridade da população (SILVA et al., 2012).

Entende-se que a gestão pública é referente a toda e qualquer atividade prevista no plano de gerenciamento do poder público, a nível municipal, estadual e/ou federal, e nessa conjuntura é essencial a interligação da gestão pública ao desenvolvimento sustentável, que trata-se de um modelo de desenvolvimento capaz de suprir as necessidades da geração atual sem comprometer a capacidade de atender a demanda das futuras gerações, em um tripé de sustentabilidade que engloba os meios sociais, econômicos e ambientais. Segundo Feil e Schreiber (2017, p. 678), "o desenvolvimento sustentável é o processo que entra em cena com base em estratégias para aproximar o sistema ambiental humano ao nível de sustentabilidade com vistas a que a vida deste complexo sistema se harmonize e perpetue ao longo do tempo".

Nesse sentido, o desenvolvimento sustentável atinge diversos setores e proporciona os mais variados benefícios ao meio ambiente e sociedade. Assim, o atual cenário da gestão dos resíduos sólidos urbanos vem integrar-se às demais temáticas da agenda ambiental proposta pelo poder público, com o intuito de promover uma adequada gestão dos resíduos pautada na sustentabilidade (BARBOSA; SILVA; LISTON, 2010).

Nesse contexto, os pequenos municípios brasileiros enfrentam grandes desafios para conseguirem promover um 
correto e eficaz gerenciamento dos resíduos sólidos urbanos que estão sob suas competências. Como também se defrontam com dificuldades em promover a implantação da Política Nacional de Resíduos Sólidos ${ }^{6}$ (PNRS), com as diretrizes, objetivos e metas propostos.

A PNRS compreende conceitos modernos de gestão de resíduos sólidos, resultando em novas ferramentas à legislação ambiental brasileira. Tem como objetivo o enfrentamento dos problemas ambientais, sociais e econômicos ocasionados em função do manejo inadequado dos resíduos sólidos, introduz a responsabilidade compartilhada dos geradores de resíduos, cria metas e institui instrumentos de planejamento em todos os níveis de governo (MMA, 2019).

Dessa maneira, é importante discutir sobre o correto gerenciamento dos resíduos sólidos e as dificuldades enfrentadas pelos pequenos municípios para implantar e executar uma apropriada gestão. Nesse contexto, vale salientar a acerca do modo de trabalho dessa questão no âmbito do setor público, a forma de como acontece o gerenciamento e implantação da PNRS e dialogar sobre as dificuldades enfrentadas por pequenos municípios em desenvolver o Plano Nacional de Resíduos Sólidos dentro da esfera municipal (BRASIL, 2019).

Assim, o presente trabalho teve como objetivo responder a seguinte pergunta problema: existe uma a gestão de resíduos sólidos urbanos do município de Itinga do Maranhão - MA, com foco na implantação da PNRS? Dessa maneira, o objetivo deste trabalho foi gestão de resíduos sólidos urbanos do município de Itinga do Maranhão - MA, com foco na implantação da PNRS. Em segundo plano, este trabalho teve como intento, compreender os procedimentos adotados na gestão pública do município em relação à promoção do desenvolvimento sustentável dessa cidade, bem como

\footnotetext{
${ }^{6}$ A Política Nacional de Resíduos Sólidos é bastante atual e contêm instrumentos importantes para permitir o avanço necessário ao País no enfrentamento dos DOI https://doi.org/10.24021/raac.v17i1.5310
}

identificar o andamento da implantação da PNRS e diagnosticar o cenário da gestão de resíduos sólidos evidenciando os possíveis entraves existentes (CUNHA; CAIXETA FILHO, 2002).

Portanto, este trabalho contribuirá para literatura no tocante a gestão de resíduos sólidos e para o mercado, servindo como um manual de como gerir os recursos sólidos aos municípios semelhantes ao pesquisado. Esta pesquisa foi do tipo qualitativa descritiva, com uma pesquisa de campo e aplicação de questionário semiestruturado. Para atingir o objetivo deste trabalho, a priori, fez-se uma revisão sobre os estudos anteriores. Posteriormente, foi aplicado um questionário aos gestores que tratam da pasta no município. Em seguida, foi analisado os dados. Por fim, constatou-se que muitos programas ainda se encontram em processo de implementação e os entraves existentes concentram-se na ausência da participação da sociedade e na escassez de incentivos federais, demandando um maior comprometimento dos gestores em busca da máxima efetivação das ações desenvolvidas.

A gestão pública detém influências profundas da administração científica, onde muito do que foi desenvolvido no âmbito público é oriundo do campo da administração (SILVA; MATTIA, 2016). A Constituição Federal de 1988 em seu art. 37 estabelece os princípios da administração pública: "A administração pública direta e indireta de qualquer dos Poderes da União, dos Estados, do Distrito Federal e dos Municípios obedecerá aos princípios de legalidade, impessoalidade, moralidade, publicidade e eficiência [...]" (BRASIL, 1988).

Seguindo os princípios estabelecidos na Constituição, a administração pública tende a atuar nos processos de organização, formulação, implementação e avaliação de políticas públicas que são de competências do Estado. Nesse contexto, o planejamento é o

principais problemas ambientais, sociais e econômicos decorrentes do manejo inadequado dos resíduos sólidos.

Vol. 17, N. 01 (2020) 
fator condicionante para o desenvolvimento de planos e programas em qualquer campo de ação da gestão pública e da administração (BRASIL, 2019). Assim, o planejamento é uma função administrativa que define os objetivos, estratégias, atividades e recursos necessários para atingir os intentos inicialmente propostos; é por meio das decisões estratégicas tomadas pela administração pública e pela elaboração dos planos, principal ponto decorrente do planejamento, que é possível o alcance das metas e objetivos (OJHA; PATEL; SRIDHARAN, 2020).

Segundo Leite e Rezende (2010), existem desafios constantes na gestão pública de municípios, que estão relacionados à indisponibilidade de informações precisas e seguras para subsidiar decisões administrativas e estudos de casos que venham a ser realizados, sendo que um banco de dados e informações acerca do gerenciamento local propicia a elaboração e controle de um planejamento estratégico ajustado as necessidades da população.

Dessa forma, observa-se a necessidade de uma gestão fundamentada em princípios legais, que promova bons resultados por meio de um correto e eficaz planejamento e de um direcionamento estratégico da gestão, de modo que, os cidadãos sejam beneficiados pelas políticas públicas implementadas e também tenham acesso e conhecimento das informações a respeito do que é executado pelo poder público, tanto para tomar ciência das ações quanto para utilizar as informações como fonte de dados para a realização de estudos e pesquisas a serem desenvolvidas em temáticas pertinentes ao setor público (FEIL; SCHREIBER, 2017).

As alterações nos modos de produção e consumo da sociedade, em função do desenvolvimento econômico e crescimento populacional, acarretam na geração de um maior quantitativo de resíduos sólidos urbanos.
A Lei N. 12.305/10 em seu art. $3^{\circ}$, inciso décimo sexto, apresenta a seguinte definição de resíduos sólidos:

XVI - resíduos sólidos: material, substância, objeto ou bem descartado resultante de atividades humanas em sociedade, a cuja destinação final se procede, se propõe proceder ou se está obrigado a proceder, nos estados sólido ou semissólido, bem como gases contidos em recipientes e líquidos cujas particularidades tornem inviável o seu lançamento na rede pública de esgotos ou em corpos d'água, ou exijam para isso soluções técnica ou economicamente inviáveis em face da melhor tecnologia disponível (BRASIL, 2010).

Os resíduos descartados todos os dias nos centros urbanos são provenientes de vários lugares que desempenham atividades diferenciadas, por isso, devem ser adotados mecanismos planejados dentro da gestão dos resíduos com coleta, transporte e acondicionamento adequados visando o bemestar e a integridade da saúde de toda a população (SILVA et al., 2014).

Nesse sentido, a Lei N. 12.305/10 em seu art. 13 classifica os resíduos sólidos em diversas categorias, quanto à origem e periculosidade (BRASIL, 2010), dando uma dimensão de quão extensa e complexa é a gestão dos resíduos sólidos, já que diferentes tipos de resíduos requerem tratamentos distintos, para que haja a garantia de um eficaz gerenciamento e conservação dos recursos naturais.

Depois de um longo processo de debates e projetos de lei que perdurou por mais de duas décadas, no ano de 2010 o Brasil conquistou um marco legal com a Lei $\mathrm{N}$. 12.305/10, que institui a PNRS. Constitui-se em uma legislação específica para a área de gestão dos resíduos sólidos, estando 
regulamentada pelo Decreto N. 7.404/10 que confere a PNRS um marco ainda mais abrangente no setor ambiental, ao estabelecer que a referida Política integre a Política Nacional do Meio Ambiente (PNMA) e articule-se com as diretrizes nacionais de saneamento básico (ROMANI; SEGALA, 2014).

De acordo com o Ministério do Meio Ambiente - MMA (2019), a lei contém instrumentos que permitem a resolução das problemáticas decorrentes dos resíduos sólidos gerados nas cidades. Apresenta proposta quanto a prática de hábitos de consumo sustentável, instrumentos para o aumento da reciclagem, reaproveitamento e destinação ambientalmente adequada dos rejeitos.

$\mathrm{O}$ art. $1^{\circ}$ da lei supracitada explana:

Art. $1^{\mathrm{o}}$ Esta Lei institui a Política Nacional de Resíduos Sólidos, dispondo sobre seus princípios, objetivos e instrumentos, bem como sobre as diretrizes relativas à gestão integrada e ao gerenciamento de resíduos sólidos, incluídos os perigosos, às responsabilidades dos geradores e do poder público e aos instrumentos econômicos aplicáveis (BRASIL, 2010).

A mencionada lei prevê a elaboração do Plano Nacional de Resíduos Sólidos em um amplo processo de mobilização e participação social, tendo vigência por prazo indeterminado com necessidade de atualização a cada quatro anos, integrando ações e mecanismos de orientação à política de resíduos sólidos do país (BRASIL, 2012).

A PNRS representa um importante salto da gestão pública voltada para as necessidades presentes no gerenciamento dos resíduos sólidos urbanos, desse modo, os municípios devem desenvolver suas atividades cumprindo seu papel e responsabilidades previstas em lei, executando uma adequada gestão com o propósito da adoção de padrões sustentáveis de produção, consumo e destinação final dos resíduos sólidos.

De um modo geral, quase todas as cidades brasileiras estão passando por um processo de crescimento desordenado, necessitando de um novo padrão de desenvolvimento com base nas definições de sustentabilidade e sua importância para o cenário atual de urbanização.

O manejo inadequado dos resíduos sólidos causa graves impactos ao meio ambiente e à sociedade, representando uma das grandes preocupações ambientais contemporâneas; dentre os problemas mais comuns pode-se citar a poluição atmosférica, odores e gases nocivos, contaminação do solo e recursos hídricos, desvalorização imobiliária e disseminação de doenças (ANDRADE; FERREIRA, 2011).

O desenvolvimento sustentável pode ser entendido como o conjunto de ações que permitem o crescimento urbano satisfazendo as demandas presentes sem comprometer as atividades das futuras gerações, seguindo as normas e legislação vigente, conservando o meio ambiente, patrimônio cultural e valores locais (YUAN; ZHANG, 2020). Para que o sistema funcione desse modo é necessária a participação da população de forma integrada, com a atuação de todos os setores, comércios, empresas e indústrias, além dos próprios órgãos do setor público (BARBOSA et al., 2010).

E dentro do contexto abordado, a reciclagem mostra-se uma das alternativas mais importantes e significativas para a minimização dos problemas decorrentes dos impactos causados ao meio ambiente pela inadequada destinação de resíduos, onde ao invés de serem descartadas grandes quantidades de resíduos faz-se o reaproveitamento dos mesmos como matériaprima para novos produtos. Ganha ênfase também as ações de recuperação de áreas degradadas e redução de volume dos resíduos 
produzidos, as quais devem ser desenvolvidas em todos os níveis: nacional, regional e local (HEMPE; NOGUERA, 2012).

É evidente que os benefícios adquiridos por meio do processo de urbanização sustentável são variados, assim, o entendimento e posicionamento cultural da sociedade em tomar consciência da importância das ações e atitudes ligadas à sustentabilidade é essencial para uma exitosa condução e reposicionamento das ações em bases sustentáveis dentro da gestão (FEIL; SCHREIBER, 2017).

A coleta seletiva dos resíduos sólidos em condições favoráveis para a reciclagem e reaproveitamento constitui-se uma forma menos insalubre da atividade de catação de materiais realizadas por associações, cooperativas e/ou por conta própria dos catadores, proporcionando para as pessoas uma forma mais digna de trabalho e inserção ao convívio em sociedade, contribuindo com a melhoria da qualidade de vida dessas pessoas (MEDEIROS, 2012).

A legislação pertinente aos resíduos sólidos é bem vasta, o que permite diversos nortes e apontamentos para o gerenciamento dos resíduos urbanos. O crucial é dar seguimento ao processo com a participação integrada dos personagens; o gestor municipal juntamente com as secretarias competentes devem promover projetos e ações que envolvam toda a população, com atividades sendo realizadas durante todo o ano com temáticas que façam a junção da educação ambiental e resíduos sólidos, para que todos sejam colaboradores em disseminar boas práticas ambientais voltadas para a conservação da natureza e seus recursos (HEMPE; NOGUERA, 2012).

É possível constatar que existem algumas barreiras em meio a esse cenário, que indicam a necessidade da reestruturação do setor em uma perspectiva de um gerenciamento mais eficaz, a partir de métodos baseados em uma tomada de decisões que permitam a otimização tática e operacional do sistema (CUNHA; CAIXETA FILHO, 2002).

A ausência de iniciativa de programas e capacitação voltadas para a sociedade, com a finalidade de promover a implementação de projetos na área de resíduos, dificulta a participação popular. Nesse contexto, torna-se fundamental a existência de políticas públicas e ações de gerenciamento dos resíduos urbanos, que são produzidos e descartados diariamente em milhares de municípios e por milhões de pessoas, no âmbito da coleta, recebimento, transporte, tratamento, recuperação e destinação final (MAIELLO; BRITTO; VALLE, 2018).

\section{MAterial e Métodos}

A presente pesquisa é de abordagem qualitativa e descritiva, foi conduzida com base em uma análise documental e realização de uma pesquisa de campo. No que diz respeito aos objetivos, esta pesquisa é classificada como exploratória e descritiva haja vista que buscou-se descrever as percepções dos entrevistados, como também se promoveu um diálogo com o tema investigado no município de Itinga do Maranhão - MA, cidade está que é fronteira do estado do Maranhão com o estado do Pará (ITINGA DO MARANHÃO, 2017). O município está localizado na mesorregião do Oeste Maranhense, microrregião de Imperatriz, com uma área territorial de $3.596,99 \mathrm{~km}^{2}$, é uma cidade relativamente nova (21 anos), emancipada em 1997 de Açailândia - MA (BRASIL, 2013). No último censo de 2010 a população totalizava 24.863 pessoas, com uma densidade demográfica de $6,94 \mathrm{hab} / \mathrm{km}^{2}$, sendo que $70,95 \%$ da população reside na área urbana (IBGE, 2010).

Ainda segundo o IBGE, somente $0,4 \%$ das residências estão situadas em vias públicas com urbanização adequada, incluindo a presença de bueiro, calçada, pavimentação e meio-fio; apenas $8 \%$ dos domicílios possuem esgotamento sanitário 
adequado e $96,82 \%$ contam com coleta de lixo disponibilizada pelo serviço de coleta pública. Estando esses aspectos dentro do foco central de estudo do presente trabalho (IBGE, 2010).

Os dados foram obtidos a partir de legislações e documentos oficiais que versam sobre o assunto em questão, e para obter as informações referentes a implantação da PNRS foi aplicado um questionário com um dos gestores da Secretaria Municipal de Meio Ambiente (SEMMA) do município no dia 10 de junho de 2019, possibilitando maior conhecimento, compreensão e análise das atividades desenvolvidas no sistema de gestão dos resíduos sólidos executado na cidade. $\mathrm{O}$ questionário semiaberto continha 10 questões que foram respondidas de forma contextualizada pelo gestor e funcionários do departamento investigado; esse instrumento de coleta de informações é importante em uma pesquisa social por garantir o anonimato ao público participante bem como facilitar a padronização e manejo dos dados (CHAER et al., 2011).

A partir dos dados primários, oriundos do questionário e dos documentos oficiais analisados, o estudo buscou identificar informações que venham responder a indagação que compõe a problemática da pesquisa, verificando quais os entraves e desafios enfrentados pelo município na gestão de resíduos sólidos urbanos e na implantação da PNRS (GÜNTHER, 2009).

Por se tratar de uma pesquisa qualitativa descritiva, com base nos parâmetros documentais da temática em questão, bem como a participação de um profissional da área do meio ambiente, o estudo aprofundou-se na temática abordada dialogando com os autores que fundamentam a pesquisa, com isso foi possível interpretar e descrever os fatos e fenômenos pertinentes contidos nos documentos e relatos do participante. Na perspectiva de gerar reflexão e conhecimento dentro desse contexto para a sociedade tanto de um modo geral quanto local (GERHARDT; SILVEIRA, 2009).

\section{Resultados E Discussão}

Com o conteúdo obtido por meio do questionário aplicado e da análise documental, foi possível verificar os aspectos que circundam a gestão dos resíduos sólidos urbanos do município de Itinga do Maranhão. De modo que, as informações obtidas são de grande valia para a avaliação do desenvolvimento e implantação da PNRS no município, servindo de subsídio para verificação da efetividade da gestão adotada, norteando também as futuras ações de gerenciamento dos resíduos sólidos.

O questionário foi elaborado para identificar e caracterizar o andamento da implantação da PNRS e os entraves existentes em meio a esse cenário. O mesmo foi aplicado com um dos gestores da SEMMA cuja função é a direção da área de licenciamento ambiental, tem graduação em engenharia ambiental e está no cargo há 36 meses; por questões éticas, optou-se por não revelar a identidade do participante. A SEMMA tem por principal objetivo coordenar as ações de gestão ambiental com a intenção de promover o desenvolvimento sustentável, de forma integrada com a participação da sociedade (ITINGA DO MARANHÃO, 2019).

A realização de um diagnóstico municipal constitui-se em um verdadeiro desafio a ser enfrentado, e tem como propósito a obtenção de dados confiáveis e suficientemente complexos que permitam o reconhecimento do problema com a maior clareza e rapidez possível, indicando as reais e viáveis possibilidades de superação (ROMANI; SEGALA, 2014).

De acordo com os documentos oficiais consultados e com as respostas obtidas por meio do questionário, constatou-se que o município possui o Plano Municipal de Gestão Integrada de Resíduos Sólidos (PMGIRS), validado pelo Decreto Municipal N. 034/2012, que "aprova o Plano Municipal de Gestão Integrada de Saneamento e Resíduos Sólidos e dá outras providências" (ITINGA DO MARANHÃO, 2012). Porém, segundo o gestor participante este documento Vol. 17, N. 01 (2020) 
encontra-se em processo de adaptação pela atual gestão.

Com relação a responsabilidade compartilhada dos geradores de resíduos, estabelecida legalmente pela PNRS, é determinado que o comprometimento pelos resíduos sólidos não é integralmente do poder público, incorporando nesse processo os fabricantes, distribuidores, comerciantes, consumidores, empresas prestadoras de serviço de limpeza, manejo e coleta de resíduos e demais atores. Constituindo-se em uma responsabilidade de todos, o poder público deve promover o planejamento adequado para uma gestão que viabilize o engajamento de empresas e da comunidade (IMPERATRIZ, 2018).

Quando questionado sobre a existência de parcerias formadas em função da responsabilidade compartilhada dos geradores de resíduos da cidade, segundo o participante, ainda encontra-se em fase de elaboração o Plano de Saneamento Ambiental participativo, com metas previstas para o $2^{\circ}$ semestre de 2019 e para o ano 2020.

A execução de determinados programas e ações são essenciais para a garantia do sucesso de todo o conjunto de ações da gestão; uma vez que são estabelecidos em lei as diretrizes e prazos, os planos de gestão deverão ser fundamentados principalmente nas exigências legais, capacidade de investimentos, capacidade gerencial, entre outros fatores (MMA, 2012). Salienta-se que, a gestão municipal promoveu a elaboração do PMGIRS, estudo de viabilidade do aterro sanitário, licenciamento (LICENÇA PRÉVIA) da área do aterro e realiza a coleta de resíduos em território urbano de competência municipal, estando essas atividades ligadas ao cumprimento das metas estabelecidas pela Lei N. 12.305/10, mesmo que não tenham decorrido dentro dos prazos legais estabelecidos.

Observa-se então que a gestão caminha rumo a efetivação das ações iniciadas para que os resultados esperados sejam concretizados. Algumas atividades encontram-se ainda em fase de adaptação, estudo e/ou implantação e outras já implementadas decorrem normalmente conforme a rotina e escala previstas no planejamento gerencial do município.

Segundo Romani e Segala (2014), os desafios com relação a gestão dos resíduos sólidos se elevam ao passo que cresce o volume de resíduos gerados, crescimento esse que acarreta em uma maior demanda dos serviços de coleta municipal. Reforçando esta ideia a Lei N. 283/2017, que institui o Código Municipal de Meio Ambiente, em seu art. 44 explana:

Art. $44 \quad \mathrm{O}$ Município deverá implantar adequado sistema de coleta, tratamento e destinação dos resíduos sólidos urbanos, incluindo coleta seletiva, segregação, reciclagem, compostagem e outras técnicas que promovam a redução do volume total dos resíduos sólidos gerados (ITINGA DO MARANHÃO, 2017).

Dessa forma, a citada Lei, nos artigos 100 e 102, também prevê a participação da comunidade, políticos, empresários, associações, ONG's, sindicatos e do poder público em condição de obrigatoriedade como meio de assegurar um futuro desejável e factível, assim como determina que a SEMMA, representante do poder público municipal, deverá incentivar a participação social nas temáticas ambientais visando garantir o êxito na implementação dos instrumentos previstos.

Diante disso, buscou-se identificar a atuação da SEMMA frente a essas premissas, salienta-se que a mesma desenvolve atividades que atendem aos elementos determinados na Lei e busca promover um maior alcance dos seus feitos, mesmo diante das adversidades presentes no campo administrativo e operacional.

Conforme os documentos analisados, no que concerne a gravimetria e classificação 
dos resíduos sólidos, diagnosticadas em uma pesquisa vinculada à SEMMA realizada no município em questão, foram identificados os principais tipos de resíduos: domiciliares; de estabelecimentos comerciais e prestadores de serviços; de limpeza urbana e entulhos. Dentro dessas tipologias, a maior percentagem é de resíduo orgânico com 43,19\% do total amostrado, o plástico tem percentual de $14 \%$ e de $17,20 \%$ para papel e papelão, podendo-se constatar que há uma real necessidade de implementação de programas de conscientização para um consumo mais racional, com foco na redução e reaproveitamento dos materiais.

Vale ressaltar que a PNRS se articula com a Política Nacional de Educação Ambiental (BRASIL, 2010). Conforme o participante, a Secretaria no ano de 2017 teve chancelado o Projeto "Sala Verde", que é coordenado pelo Departamento de Educação Ambiental do Ministério do Meio Ambiente (DEA/MMA) e consiste no incentivo à implantação de espaços socioambientais para atuarem como potenciais Centros de Informação e Formação Ambiental. O gestor relata que a dimensão básica de qualquer Sala Verde é a disponibilização e democratização da informação ambiental e a busca por maximizar as potencialidades dos materiais distribuídos, colaborando para a construção de um espaço, que além do acesso à informação, ofereça a possibilidade de reflexão e construção do pensamento/ação ambiental.

A SEMMA realiza também reuniões e palestras de conscientização voltadas para os comerciantes e comunidade local, com o interesse de sensibilizar a sociedade por meio do conhecimento da importância e necessidade de um adequado gerenciamento dos resíduos sólidos, que envolve as ações iniciais de separação e descarte do lixo até sua correta destinação final, elucidando os pontos de extrema relevância na implantação da PNRS com relação as ações já realizadas e propostas pela gestão.

Nesse sentido, verifica-se que a gestão busca conhecer os tipos de resíduos gerados no território de sua competência, bem como, o percentual de cada categoria dos materiais coletados cujo reaproveitamento e reciclagem sejam viáveis; promove ações de educação ambiental e conscientização para os diversos setores públicos e em diferentes espaços com $\mathrm{o}$ intuito de disseminar conhecimento $\mathrm{e}$ sensibilizar a população em uma maior escala, fazendo com que as boas práticas voltadas para o gerenciamento dos resíduos sólidos sejam realizadas pela sociedade de modo geral. Reiterando essa ideia, o Art. $7^{\circ}$ da Lei N. 12.305/10 apresenta alguns dos objetivos da PNRS:

I - proteção da saúde pública e da qualidade ambiental;

II - não geração, redução, reutilização, reciclagem e tratamento dos resíduos sólidos, bem como disposição final ambientalmente adequada dos rejeitos;

[...]

VI - incentivo à indústria da reciclagem, tendo em vista fomentar o uso de matérias-primas e insumos derivados de materiais recicláveis e reciclados;

VII - gestão integrada de resíduos sólidos;

VIII - articulação entre as diferentes esferas do poder público, e destas com o setor empresarial, com vistas à cooperação técnica e financeira para a gestão integrada de resíduos sólidos; [...] (BRASIL, 2010).

Nessa perspectiva, o presente órgão ambiental onde executou-se o estudo de caso, realiza o gerenciamento participativo dos resíduos sólidos, incentiva a coleta seletiva e destinação adequada dos materiais. Sendo oportuno também ressaltar que atualmente o município conta com 15 catadores registrados; os mesmos trabalham devidamente uniformizados e fazem o uso de equipamentos de proteção individual (EPI's) durante suas atividades. 
No que se refere a coordenação das ações de coleta e destinação ambientalmente adequada dos resíduos, o participante relatou que a gestão promove a coleta municipal de resíduos por meio de uma empresa terceirizada responsável; o município ainda não conta com uma instituição/associação recicladora formalizada, estando em fase de implantação uma cooperativa de recicláveis, denominada COOPERLIXO. Ainda segundo o participante, o lixão que existia dentro da área urbana da cidade, foi substituído por um local específico para receber os resíduos coletados; e encontra-se em fase de licenciamento e implantação o aterro sanitário municipal.

A coleta de materiais recicláveis no município realizada pelos catadores na área do aterro sanitário, está resultando na retirada média de $7.500 \mathrm{~kg}$ de plástico por mês do meio ambiente, podendo chegar até pouco mais de $8.000 \mathrm{~kg}$ em alguns períodos, com uma média semanal de $2.000 \mathrm{~kg}$. Até o momento o plástico tem sido o único material coletado em maior notoriedade, por conta da ausência de uma prévia separação do lixo descartado ainda nos ambientes domiciliares e comerciais, o que dificulta bastante a atividade dos catadores; o papel e papelão, por exemplo, ficam praticamente inutilizados por entrarem em contato com outros resíduos que lhe conferem um alto teor de umidade.

$O$ repasse de informações acerca dos resíduos sólidos urbanos por parte dos municípios, de acordo com suas competências, é previsto na Lei N. 12.305/10 conforme o art. 12 a seguir:

Parágrafo único. Incumbe aos Estados, ao Distrito Federal e aos Municípios fornecer ao órgão federal responsável pela coordenação do Sinir todas as informações necessárias sobre os resíduos sob sua esfera de competência, na forma e na periodicidade estabelecidas em regulamento (BRASIL, 2010).
Assim, segundo o gestor o departamento ambiental do município concede as informações para a Secretaria Municipal de Saúde, órgão responsável pelo controle de dados, que repassa diretamente ao Sistema Nacional de Informações sobre a Gestão dos Resíduos Sólidos - SINIR.

O SINIR é um dos instrumentos da PNRS, que somado aos demais sistemas de coordenação de resíduos compreendem informações atualizadas quanto a origem, transporte e destinação final. O Sistema atua de forma conjunta com o MMA, articulando as ações e sistematizando os dados coletados acerca do gerenciamento dos resíduos sólidos, com informações oriundas dos Estados, Distrito Federal e Municípios (SINIR, 2018).

Considerando que a PNRS prevê a adoção de soluções consorciadas intermunicipais ou mesmo individualizadas dos municípios para a gestão dos resíduos sólidos (BRASIL, 2010), o relato do gestor evidencia que a SEMMA procura viabilizar a montagem de um termo de referência direcionado a Política de Resíduos Sólidos dos Serviços de Saúde, estando a ação em fase de levantamento técnico; para os demais tipos de resíduos estuda-se a possibilidade da realização de consórcios com outros municípios, dentro de uma viabilidade intermunicipal.

O MMA orienta que os arranjos territoriais entre municípios, com a finalidade de compartilhar atividades e serviços, possibilitam a maximização de recursos humanos, infraestrutura e capital financeiro, promovendo economia de escala em função da alta redução de custos; trata-se de uma forma consorciada de planejar, regular, fiscalizar e prestar os serviços conforme com a realidade de cada local com maior capacidade tecnológica, profissional e de investimentos na gestão de resíduos sólidos, com base no estabelecimento de critérios relevantes para ambos os municípios integrantes do arranjo (MMA, 2012).

Nessa conjuntura, constata-se que o cumprimento dos objetivos e determinações 
legais associado ao engajamento da gestão municipal em prol do alcance dos intentos definidos proporcionam uma maior efetividade da ações referentes a implantação da PNRS, sendo primordial o constante monitoramento e aperfeiçoamento das atividades para que os propósitos de diminuição da geração de resíduos, maior reaproveitamento, aumento da reciclagem, consumo sustentável, destinação ambientalmente adequada, entre outros, sejam atingidos.

Conforme o relato do gestor, dentre os principais pontos de dificuldades encontrados no processo de implantação da PNRS no município em questão, destaca-se a ausência de participação da sociedade e inviabilidade econômica, em função da falta de sensibilidade por parte da população e da escassez de incentivos federais, que se consolidam nos maiores desafios encontrados dentro da gestão pública voltada para o gerenciamento dos resíduos sólidos.

Ao observar as falas do participante, Barros e Souza (2017) fazem algumas observações referentes a questão, um dos maiores entraves desse cenário se concentra justamente na tímida participação da população, que acaba não contribuindo da forma esperada dentro do planejamento previsto pela gestão, tornando imprescindível a adoção de ações e programas de educação ambiental para que a população se sensibilize e tenha consciência de seus direitos e deveres com a gestão dos resíduos sólidos, com base em um maior comprometimento por parte dos gestores municipais.

Os princípios legais associados aos culturais podem constituir-se em verdadeiras barreiras para o processo de gestão, além de que o escasso comprometimento financeiro, geralmente uma pequena porcentagem da receita total, torna ainda mais difícil a realização das práticas pretendidas no gerenciamento dos resíduos. Assim, abrem-se lacunas em meio as ações que deveriam ser efetivadas, demandando o desenvolvimento de programas que tenham foco e investimentos bem direcionados (MAIELLO et al., 2018).

Essas dificuldades enfrentadas no âmbito local para a implantação da PNRS entorno da questão cultural da sociedade, envolvendo a tímida e/ou ausente participação popular em contribuir com as ações previstas e reduzir o quantitativo de lixo produzido, carência de recursos, que contribui diretamente para as deficiências na gestão, e até mesmo prazos legais estabelecidos, falta de capacitação profissional e ausência de integração municipal, consistem-se em problemas que entravam a gestão de resíduos sólidos dentro da esfera municipal.

\subsection{Considerações Finais}

Com a análise da gestão dos resíduos sólidos do município de Itinga do Maranhão, atendendo o objetivo proposto, pode-se verificar o andamento da implantação da PNRS bem como diagnosticar o cenário da gestão adotada em face aos entraves existentes. A SEMMA, por meio dos gestores responsáveis, desenvolve atividades e programas voltados para um gerenciamento adequado dos resíduos, com a intenção de promover o desenvolvimento sustentável, bem como atender as metas e diretrizes que compõem a PNRS.

Com base no estudo documental e com a participação do gestor ao responder o questionário, denota-se que o município busca incorporar em suas atividades a participação social, assim como, desenvolve ações voltadas para a Educação Ambiental buscando o engajamento da comunidade. A gestão conta com o PMGIRS em fase de adaptação, aterro sanitário e uma cooperativa de recicláveis em estágio de licenciamento e implantação, e sinaliza a intenção de adoção de medidas consorciadas intermunicipais para $\mathrm{o}$ gerenciamento dos resíduos sólidos. Essas circunstâncias evidenciam que as atividades executadas em consonância à PNRS ainda se encontram fase de desenvolvimento e 
precisam ser concretizadas para o efetivo cumprimento dos objetivos.

De acordo com o gestor os entraves enfrentados pela gestão se concentram principalmente em torno da ausência da participação e sensibilidade da população e pela falta de incentivos federais, que inibem o adequado andamento das atividades e programas contidos no plano de gestão. Por esses e outros motivos, é essencial a permanente prática de ações de sensibilização e educação ambiental, investimento em infraestrutura e capacitação profissional para um melhor aproveitamento dos recursos humanos e financeiros, denotando a necessidade de um crescente comprometimento por parte dos gestores públicos.

É interessante salientar que a gestão pública, em suas diferentes esferas, precisa buscar continuamente a efetivação prática do que está estabelecido documentalmente e legitimado. Ressalta-se ainda que, a temática abordada é de grande relevância a nível global, nacional e local, uma vez que, discute uma questão que abrange uma problemática bastante presente na sociedade contemporânea. Diante disso, deve ser motivação de outros estudos e pesquisas que venham cada vez mais elucidar os aspectos pertinentes ao campo analisado.

\section{Agradecimentos}

Ao Programa de Pós Graduação em Gestão Pública da Universidade Federal do Maranhão (UFMA) e a Prefeitura Municipal do Itinga do Maranhão pelo apoio na realização deste trabalho.

\section{REFERÊNCIAS}

ANDRADE, Rafael Medeiros de; FERREIRA, João Alberto. A gestão de resíduos sólidos urbanos no Brasil frente às DOI https://doi.org/10.24021/raac.v17i1.5310 questões da globalização. Revista Eletrônica do Prodema, Fortaleza-CE, n. 1, v. 6, p. 7-22, 2011.

BARBOSA, Agoncilio Correia; SILVA, Cleiuda Paes da; LISTON, Rose Cristiani Franco Seco. GESTÃo PÚBLICA E DESENVOLVIMENTO SUSTENTÁVEL: A importância da implantação de plano diretor no ato de criação de um município. Revista Científica da AJES, Juína-MT, n. 1, v. 1, p. 6-22, 2010.

BARROS, Hilquias Sabino; SOUZA, Francisca Leidiana de. Resíduos Urbanos: Desafios para Implantação da Política Nacional de Resíduos Sólidos no Município de Mossoró-RN. Geografia, Ensino \& Pesquisa, n. 2, v. 21, p. 188-196, 2017.

BRASIL. Atlas do Desenvolvimento Humano no Brasil. 2013. Disponível em: http://atlasbrasil.org.br/2013/pt/perfil_m/iting a-do-maranhao_ma. Acesso em: 18 jun. 2019.

BRASIL. Constituição Federal de 1988. Promulgada em 5 de outubro de 1988. Disponível em: http://www.planalto.gov.br/ccivil_03/constitu icao/constituicaocompilado.htm. Acesso em: 17 jun. 2019.

BRASIL. Lei 12.305/10. Política Nacional dos Resíduos Sólidos - PNRS. Brasília, 2010. Disponível em: http://www.planalto.gov.br/ccivil_03/_ato20 07-2010/2010/lei/112305.htm. Acesso em: 17 jun. 2019.

BRASIL. Plano Nacional de Resíduos Sólidos. Brasília, 2012.

Vol. 17, N. 01 (2020) 
CHAER, Galdino; DINIZ, Rafael Rosa Pereira; RIBEIRO, Elisa Antônia. A técnica do questionário na pesquisa educacional. Evidência, Araxá-MG, n. 7, v. 7, p. 251-266, 2011.

CHIAVENATO, Idalberto. Administração geral e pública. Rio de Janeiro: Elsevier, 2008.

CUNHA, Valeriana; CAIXETA FILHO, José Vicente. GERENCIAMENTO DA COLETA DE RESÍDUOS SÓLIDOS URBANOS: Estruturação e aplicação de modelo não-linear de programação por metas. Gestão e Produção, n. 2, v. 9, p. 143161, 2002.

FEIL, Alexandre André; SCHREIBER, Dusan. SUSTENTABILIDADE E DESENVOLVIMENTO SUSTENTÁVEL: desvendando as sobreposições e alcances de seus significados. Cadernos EBAPE.BR, Rio de Janeiro-RJ, n. 3, v. 14, p. 667-681, 2017.

GERHARDT, Tatiana Engel; SILVEIRA, Denise Tolfo. Métodos de pesquisa. Porto Alegre: Editora da UFRGS, 2009.

GÜNTHER, Hartmut. Pesquisa qualitativa versus pesquisa quantitativa: Esta é a questão? Psicologia: Teoria e Pesquisa, Brasília, n. 2, v. 22, p. 201-210, 2006.

HEMPE, Cléa; NOGUERA, Jorge Orlando Cuellar. A Educação Ambiental e os Resíduos Sólidos Urbanos. Revista Eletrônica em Gestão, Educação e Tecnologia Ambiental, n. 5, v. 5, p. 682-695, 2012.
IMPERATRIZ. Plano Municipal de Gestão Integrada de Resíduos Sólidos - PMGIRS. Imperatriz-MA， 2018. Disponível em: https://d2uzqu0gkpnx87.cloudfront.net/site/n otify/semmarh/leimunicipal/VERS\%C3\%83 O_FINAL_PMGIRS_-_IMPERATRIZ_pdf. Acesso em: 02 jul. 2019.

INSTITUTO BRASILEIRO DE GEOGRAFIA E ESTATÍSTICA - IBGE. Censo Demográfico. 2010. Disponível em: https://cidades.ibge.gov.br/brasil/ma/itingado-maranhao/panorama. Acesso em: 18 jun. 2019.

ITINGA DO MARANHÃO. Decreto Municipal N. 034, de 01 de agosto de 2012. Itinga do Maranhão, 2012.

ITINGA DO MARANHÃO. Lei N. 283/2017, de 13 de outubro de 2017. Itinga do Maranhão, 2017. Disponível em: http://itinga.ma.gov.br/upload/plano_ambient al/34138.pdf. Acesso em: 01 jul. 2019.

ITINGA DO MARANHÃO. Secretaria de Meio Ambiente. Itinga do Maranhão, 2019. Disponível em: http://www.itinga.ma.gov.br/secretaria/secret aria-de-meio-ambiente. Acesso em: 01 jul. 2019.

LEITE, Leonardo de Oliveira; REZENDE, Denis Alcides. Modelo de gestão municipal baseado na utilização estratégica de recursos da tecnologia da informação para a gestão governamental: formatação do modelo e avaliação em um município. Revista de Administração Pública, Rio de Janeiro-RJ, n. 2, v. 44, p. 459-493, 2010. 
MAIELLO, Antonella; BRITTO, Ana Lúcia Nogueira de Paiva; VALLE, Tatiana Freitas. Implementação da Política Nacional de Resíduos Sólidos. Revista de Administração Pública, Rio de Janeiro-RJ, n. 1, v. 52, p. 2451, 2018.

MINISTÉRIO DO MEIO AMBIENTE MMA. Gestão de Resíduos. Brasília, 2019. Disponível em: http://www.mma.gov.br/responsabilidadesocioambiental/a3p/eixostematicos/gest $\%$ C3\%A3o-adequada-dosres\%C3\%ADduos. Acesso em: 11 jun. 2019.

MINISTÉRIO DO MEIO AMBIENTE MMA. Planos de Gestão de Resíduos Sólidos: Manual de orientação. Brasília, 2012.

MINISTÉRIO DO MEIO AMBIENTE MMA. Política Nacional de Resíduos Sólidos. Brasília, 2019. Disponível em: http://www.mma.gov.br/pol\%C3\%ADticade-res\%C3\%ADduos-s\%C3\%B3lidos.

Acesso em: 15 jun. 2019.

OJHA, Divesh; PATEL, Pankaj C.; SRIDHARAN, Sri V. Dynamic strategic planning and firm competitive performance: A conceptualization and an empirical test. International Journal of Production Economics, v. 222, p. 107509, 2020.

ROMANI, Andrea Pitanguy de; SEGALA, Karin. Planos de resíduos sólidos: desafios e oportunidades no contexto da Política Nacional de Resíduos Sólidos. Rio de Janeiro: IBAM, 2014.
SILVA, Denise Felício; SPERLING, Eduardo Von; BARROS, Raphael Tobias de Vasconcelos. Avaliação do gerenciamento dos resíduos de serviços de saúde em municípios da região metropolitana de Belo Horizonte (Brasil). Eng Sanit Ambient, n. 3, v. 19, p. 251-262, 2014.

SILVA, Harley; BARBIERI, Alisson Flávio; MONTE-MÓR, Roberto L. Demografia do consumo urbano: um estudo sobre a geração de resíduos sólidos domiciliares no município de Belo Horizonte. Revista Brasileira de Estudos de População, n. 2, v. 29, p. 421-449, 2012.

SILVA, Raphaela Reis Conceição Castro; MATTIA, Clenia de. Ciência administrativa e gestão pública: uma crítica à primazia do privado em relação ao público. Cadernos EBAPE.BR, Rio de Janeiro-RJ, n. 4, v. 14, p. 1054-1065, 2016.

SISTEMA NACIONAL DE INFORMAÇÕES SOBRE A GESTÃO DOS RESÍDUOS SÓLIDOS - SINIR. Sobre o SINIR. Brasília, 2018. Disponível em: http://sinir.gov.br/index.php/component/cont ent/article/2-uncategorised/117-sistemanacional-de-informacoes-sobre-a-gestao-dosresiduos-solidos-sinir. Acesso em: 02 jul. 2019.

YUAN, Baolong; ZHANG, Yang. Flexible environmental policy, technological innovation and sustainable development of China's industry: The moderating effect of environment regulatory enforcement. Journal of Cleaner Production, v. 243, p. 118543, 2020. 